\title{
Study of tissue inflammatory response in different mice strains infected by dematiaceous fungi Fonsecaea pedrosoi*
}

\author{
Marilia Marufuji Ogawa ${ }^{1}$, Mario Mariano ${ }^{2}$, Maria Regina Regis Silva ${ }^{3}$, Milvia Maria Simões e Silva \\ Enokihara ${ }^{3}$, Nilceo Schwery Michalany ${ }^{3}$, Angela Satie Nishikaku4, Agenor Messias Silvestre ${ }^{5}$, \\ Jane Tomimori ${ }^{1}$
}

DOI: http:/ / dx.doi.org/10.1590/abd1806-4841.20197326

\begin{abstract}
BACKGROUND: Diseases caused by melanized fungi include mycetoma, chromoblastomycosis and phaeohyphomycosis. This broad clinical spectrum depends on the dynamic interactions between etiologic agent and host. The immune status of the host influences on the development of the disease, as, an exemple. phaeohyphomicosis is more frequently observed in immunocompromised patients.

OвлестіvEs: Examine the histological inflammatory response induced by Fonsecaea pedrosoi in several different strains of mice (BALB/c, C57BL/6, Nude and SCID, and reconstituted Nude).

Methods: Fonsecaea pedrosoi was cultivated on agar gel and a fragment of this gel was implanted subcutaneously in the abdominal region of female adult mice. After infection has been obtained, tissue fragment was studied histopathologically.

Results: There were significant changes across the strains, with the nodular lesion more persistent in Nude and SCID mice, whereas in immunocompetent mice the lesion progressed to ulceration and healing. The histopathological analysis showed a significant acute inflammatory reaction which consisted mainly of neutrophils in the initial phase that was subsequently followed by a tuberculoid type granuloma in immunocompetent mice.

StUdy Limitations: There is no a suitable animal model for chromoblastomycosis.

Conclusions: The neutrophilic infiltration had an important role in the containment of infection to prevent fungal spreading, including in immunodeficient mice. The fungal elimination was dependent on T lymphocytes. The re-exposure of C57BL/6 mice to Fonsecaea pedrosoi caused a delay in resolving the infection, and appearance of muriform cells, which may indicate that re-exposure to fungi, might lead to chronicity of infection.
\end{abstract}

Keywords: Chromoblastomycosis; Dermatomycoses; Immunosuppression; Models, animal; Phaeohyphomycosis

\section{INTRODUCTION}

Melanized or dematiaceous fungi cause three distinct subcutaneous diseases in humans: mycetoma, chromoblastomycosis and phaeohyphomycosis. ${ }^{1}$ Although clinically and histologically different, they can be considered as a spectral disease, since dematiaceous fungi can cause any of those three mycoses, and the fungus
F.pedrosoi is an important agent of chromoblastomycosis and subcutaneous phaeohyphomycosis. ${ }^{2-5}$

The host's immune response is one of the factors that will determine the development of infectious diseases. The interaction between the fungal agent and the innate immunity will drive the

\footnotetext{
Received 09 June 2017.

Accepted 03 November 2017.

* Work conducted at the Department of Dermatology, Universidade Federal de São Paulo, São Paulo (SP), Brazil. Financial support: None.

Conflict of interest: None.

Department of Dermatology, Universidade Federal de São Paulo, São Paulo (SP), Brazil.

Department of Microbiology, Immunology and Parasitology, Universidade Federal de São Paulo, São Paulo (SP), Brazil.

Department of Pathology, Universidade Federal de São Paulo, São Paulo (SP), Brazil.

Special Laboratory of Mycology, Universidade Federal de São Paulo, São Paulo (SP), Brazil.

Department of Health II, Universidade Nove de Julho, São Paulo (SP), Brazil.
}

MAILING AdDREss:

Marilia Marufuji Ogawa

E-mail: mariliaogawa@uol.com.br; mariliaogawa@gmail.com

C2019 by Anais Brasileiros de Dermatologia 
primary host response to the pathogen. Neutrophils are an essential cell population of the phagocyte system which are involved in the host's defense against fungal infection. They are the first cells to be recruited during infection, with great ability of destroying the pathogen. In dematiaceous fungal infection, the role of neutrophils is still controversial. For example, Rozental et al. ${ }^{6}$ observed the capacity in vitro of mice neutrophils in effectively destroying F. pedrosoi through the activation of respiratory burst. However, Schnitzler et al. ${ }^{7}$ showed Exophiala dermatitidis resistance to the phagocytic activity of human neutrophils in vitro.

The interaction between the innate and adaptive responses is also important to generate an efficient protection against fungal pathogens. The main component of adaptive immunity is T-cell response, since it regulates the balance between tolerance and inflammation. In chromoblastomycosis, there is correlation between cell-mediated tissue reactions and different clinical forms: Th2-type immune response was seen in verrucous lesions, while Th1-type immune response in atrophic lesions. ${ }^{8}$ Furthermore, patients with severe chromoblastomycosis showed Th2 cytokines, whereas the mild forms showed Th1 cytokines. ${ }^{9}$ In vitro, CD4-defficient mice progressed to a more severe disease when infected by F. pedrosoi. ${ }^{10}$ Therefore, it seems that the host displays a distinct scenario of immunological makeup to deal with the fungal agent. That way, the interactions between pathogenic fungi and host represent a complex interaction that is critical in determining the clinical outcome.

To study the relationship between the immunological status of the host and the infectious results, different strains of mice (BALB/c, C57BL/6, Nude and SCID) were infected with F. pedrosoi for clinical and histologic investigation, observing the role of neutrophils, B-cells and T-cells during the inflammatory response.

\section{METHODS}

\section{Animals}

Four different strains of female mice were used, 10 to 12 weeks old, and six mice for each group. Immunocompetent BALB/C and C57BL/ 6 mice were provided by CEDEME (Unifesp, SP, Brazil). The other two strains of immunodeficient mice, actinic Nude mice $(\mathrm{nu} / \mathrm{nu})$ and severe combined immunodeficiency (SCID) mice were obtained from CEMIB (UNICAMP, SP). Animal studies were approved by the Ethics Committee $n^{\circ} 1809 / 08$.

Adoptive transfer of thymocytes from BALB/c mice to Nude mice

The reconstitution of Nude mice (Nude-r) was performed with eight-week old BALB/c mice thymus, which were removed and macerated with RPMI 1640 medium (Sigma, Missouri). The thymus was centrifuged with hemolytic buffer, the cells were suspend-

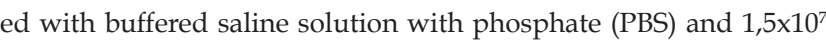
cells were transferred to Nude mice intravenously. To validate the transfer of T-cells to Nude mice, the spleen of reconstituted Nude mice was analyzed after 7,21 and 28 days by flow cytometry (FACS Aria ${ }^{\mathrm{TM}} \mathrm{II}$, Becton Dickinson, NJ, USA).

\section{Micro-organism}

The F. pedrosoi strain was provided by the Department of Microbiology, Immunology and Parasitology (Unifesp). The material was obtained from a patient with chromoblastomycosis con- firmed by histology, with a culture in Sabouraud agar suggestive for Fonsecaea spp. these fungi were cultivated in Sabouraud dextrose agar medium (DASD, DIFCO, M, USA) with $80 \mathrm{mg} / \mathrm{L}$ gentamicin at $30^{\circ} \mathrm{C}$. The molecular identification of the fungus was done through sequencing of the internal transcribed space region of the ribosomal DNA to confirm the species.

Murine experimental infection with $F$. pedroso $i$ with the agar-implantation method

The agar-implantation method was based on the protocol described by Miyaji \& Nishimura. ${ }^{11}$ After a good growth of hyphae was confirmed, the agar gel was cut into $3 \mathrm{~mm}$ squares and inserted into the subcutaneous tissue of the abdominal region of the mice after anesthesia.

\section{Experiment I}

The experiment consisted in a clinical and histologic analysis of each of the different mice strains infected with F. pedrosoi. The fungi were introduced in the subcutaneous tissue of the abdominal region, according to the method described above. BALB/c, C57BL/6, Nude and SCID and Nude-r mice were evaluated, and the skin samples were collected 7, 14, 21 and 28 days after fungal implantation.

Experiment II

Clinical and histologic analyses were performed in C57BL/6 mice infected with F. pedrosoi in two different sites: F. pedrosoi was implanted in the subcutaneous tissue of the back of C57BL/ 6 and, after 2 weeks, the mice were reexposed to the fungus through implantation of the agar block into the subcutaneous tissue of the abdominal region to observe if the previous contact with the fungi could affect the cure process of the second inoculation site. The skin samples from the abdominal region were collected on days 10, 20 and 30 after the second implantation.

Histologic analysis

Skin samples were fixed in 10\% neutral buffered formalin, incorporated in plastic resin. The sections of micrometric tissue were stained with Hematoxylin \& eosin, Grocott and Fontana-Masson and analyzed by three pathologists. Tissue inflammatory reactions were assessed by the presence of granuloma, fibrosis and necrosis, as well as by the analysis of host and fungal cell populations. The inflammatory process around the gel with fungi was measured with a graduated glass slide. To calculate the inflammatory area, two measures were performed: the larger axis and the secondary axis. Neutrophilic cells were counted in the most significant field (hot spot) with high magnification $(x 400)^{11}$. Cell count was based in crosses of + (one cross) to ++++ (four crosses) as follows: zero to 10 cells per field (+), 11 to 20 cells per field $(++), 21$ to 30 cells per field $(+++)$ and more than 30 cells per field $(++++)$.

\section{Statistical analysis}

To compare the inflammatory area among different mice strains and the post-infection time, variance analysis with two fixed factors and LSD method for multiple comparisons were performed. We used the Kruskal-Wallis test to compare the number of neutrophils and of mice strains for each post-infection period. To examine the correlation between neutrophil count and 2 groups of mice, reexposed and non-reexposed to fungi for each period after the infection, we used the Mann-Whitney test. The difference was considered statistically significant in $\mathrm{p}<0.05$. 


\section{RESULTS}

Clinical aspects of the experimental infection with F. pedrosoi

The lesion caused by the F. pedrosoi inoculum showed the following features over 28 days: firm nodule, ulceration and healing. Comparing immunocompetent and immunodeficient mice, there were marked differences in the clinical course of the lesions caused by the fungal infection. None of the animals developed systemic spread. BALB/c, C57BL/6 and Nude-r showed the same clinical and histologic changes.

On day 7, all mice had a nodule on the inoculum site (Figures $1 \mathrm{~A}-1 \mathrm{C})$ that progressed to ulceration on day 14 (Figures 1D and 1E), except in SCID mice (Figure 1F). On day 28, the lesion was completely healed in BALB/c and C57BL/ 6 mice (Figure 1G), while in Nude and SCID, the lesion persisted as a nodule (Figures $1 \mathrm{H}$ and $1 \mathrm{I})$. pedrosoi

Histologic analysis if the experimental infection with $F$.

\section{Experiment I}

The evaluation of the inflammatory area around fungi in different mice groups showed a significant reduction in the inflam- matory area from day 7 to 28 in all mice groups, except for Nude and SCID mice ( $p<0.005$ - Figure 2$)$. There was no significant reduction of these measures on days 7, 14, 21 e 28 in the immunocompromised mice.

On day 7, histology showed a marked acute inflammatory reaction, mainly made by neutrophils that surrounded the block of agar with fungi and it was more intense in BALB/c (Figure 2A), C57BL/ 6 and Nude-r mice when compared to Nude (Figure 2B) and SCID ( $p<0.005$ - Figure $2 C)$. It was interesting to observe the presence of vacuolated macrophages in SCID mice. In this period, the beginning of a repair tissue made of vascular neoformation and fibroblasts was seen in BALB/c, C57BL/ 6 and Nude-r mice. On day 14 (Figures 2D-2F), the tuberculoid granuloma was present in immunocompetent mice (BALB/c and C57BL/6) and Nude-r mice. In Nude mice, neutrophil infiltration predominated with a subtle granulomatous response that persisted on day 28 (Figure $2 \mathrm{H}$ ), significantly different than BALB/c (Figure 2G), C57BL/ 6 and Nude-r mice, in which the granuloma disappeared. The granulomatous infiltration was not observed in SCID mice (Figure 2I). Fungal extrusion (Figures 3A-3F) was observed in all animals on days 7 and 14, except in SCID mice. On day 28 (Figures 3G-3I), the fungi were
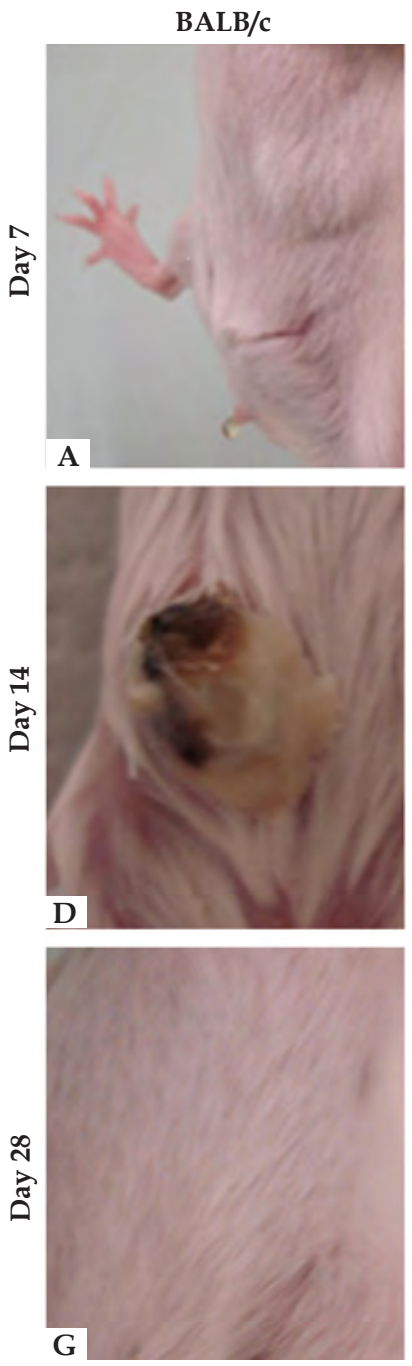
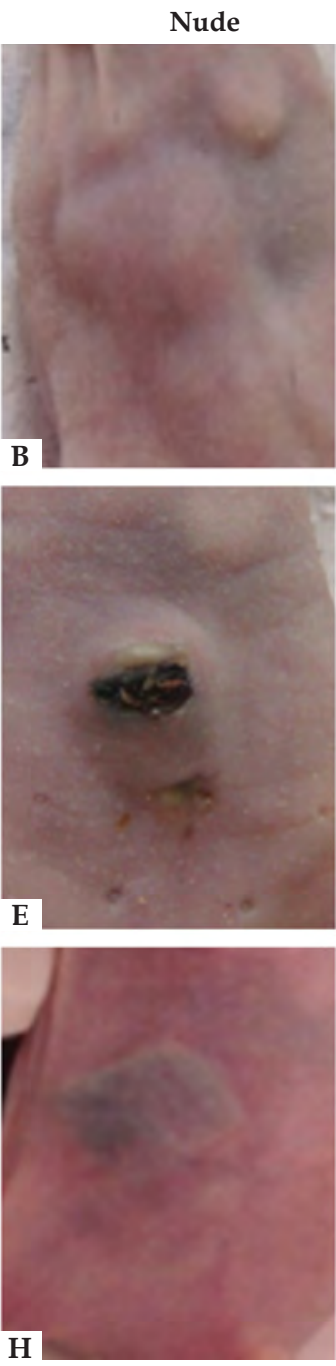
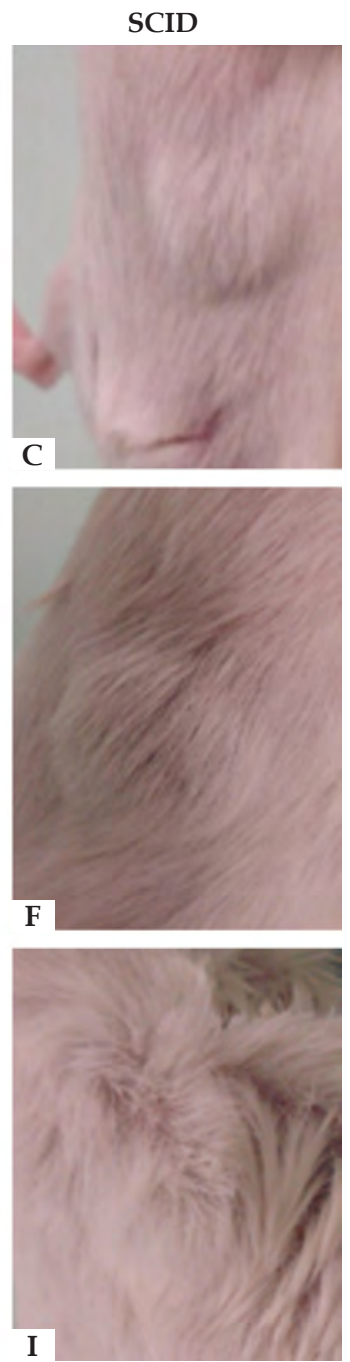

Figure 1: Abdominal region of BALB/c, Nude and SCID mice at 7, 14 and 28 days after subcutaneous implantation of the fungus $\mathrm{F}$. pedrosoi. Day 7: (A, B, C) BALB/c, Nude and SCID, respectively, showed a nodular lesion. Day 14: (D, E) BALB/c and Nude, respectively, showed ulceration of the nodule with extrusion of a black material and (F) SCID mice, the presence of nodule without ulceration. Day 28: (G) BALB/c showed disappearance of the nodule and $(\mathbf{H}, \mathbf{I})$ Nude and SCID, respectively, showed persistence of the nodule 
completely destroyed by BALB/c and Nude-r mice but were still present in Nude and SCID mice.

On the $7^{\text {th }}$ day, Grocott stain revealed hyphae as a long line along the agar gel in immunocompetent BALB/c mice (Figure 3A) and Nude-r mice. In contrast, hyphae penetrated muscle tissue in Nude and SCID mice (Figures 3E and 3F), and the fungi remained intact during the 28-day period in immunocompromised mice (Figures $3 \mathrm{H}$ and $3 \mathrm{I}$ ).

\section{Experiment II}

In this experiment, F. pedrosoi was inoculated into 2 distinct sites in C57BL/ 6 mice and fungal reexposure was done after an interval of 14 days. The objective of this study was to compare the histologic differences seen on days 10, 20 and 30 among mice exposed to fungi only once and mice that were reexposed to fungi. In reexposed mice, the lesion was compared from the second site of inoculation. Graph 1 represents the measurement of the inflammatory area of the 2 mice groups. On day 10, we observed that the inflammatory area of reexposed mice was significantly smaller than the one observed in non-reexposed mice $(p=0.015)$. The inflammatory area on day 10 was larger than on days 20 and 30 in both groups.
On day 10, the following results were observed: C57BL/6 mice with no reexposure had a high amount of neutrophils surrounding fungi with a compact granulomatous infiltrate (Figure $4 \mathrm{~A})$. In contrast, reexposed mice showed a diffuse granulomatous infiltration and the neutrophilic infiltrate was less intense (Figure 4B). On day 20, non-reexposed mice were capable of destroying the fungi and also showed a small amount of granulomatous infiltration (Figure 4C). On the other hand, fungi were still present and there was no change in the inflammatory infiltration process in the group of reexposed mice (Figure 4D). On day 30, no fungi were observed in neither group of mice, and the granulomatous infiltration persisted only in reexposed mice. It is also important to point out the presence of muriform cells in the group that was reexposed on day 10 (Figure 4E).

\section{DISCUSSION}

Our objective in the present study was to observe the interaction between the host and the infectious agent $F$. pedrosoi. To analyze the influence of the immune response of the host during the infection, we evaluated the inflammatory response and the ability to overcome the infection in strains of immunocompetent or immu-
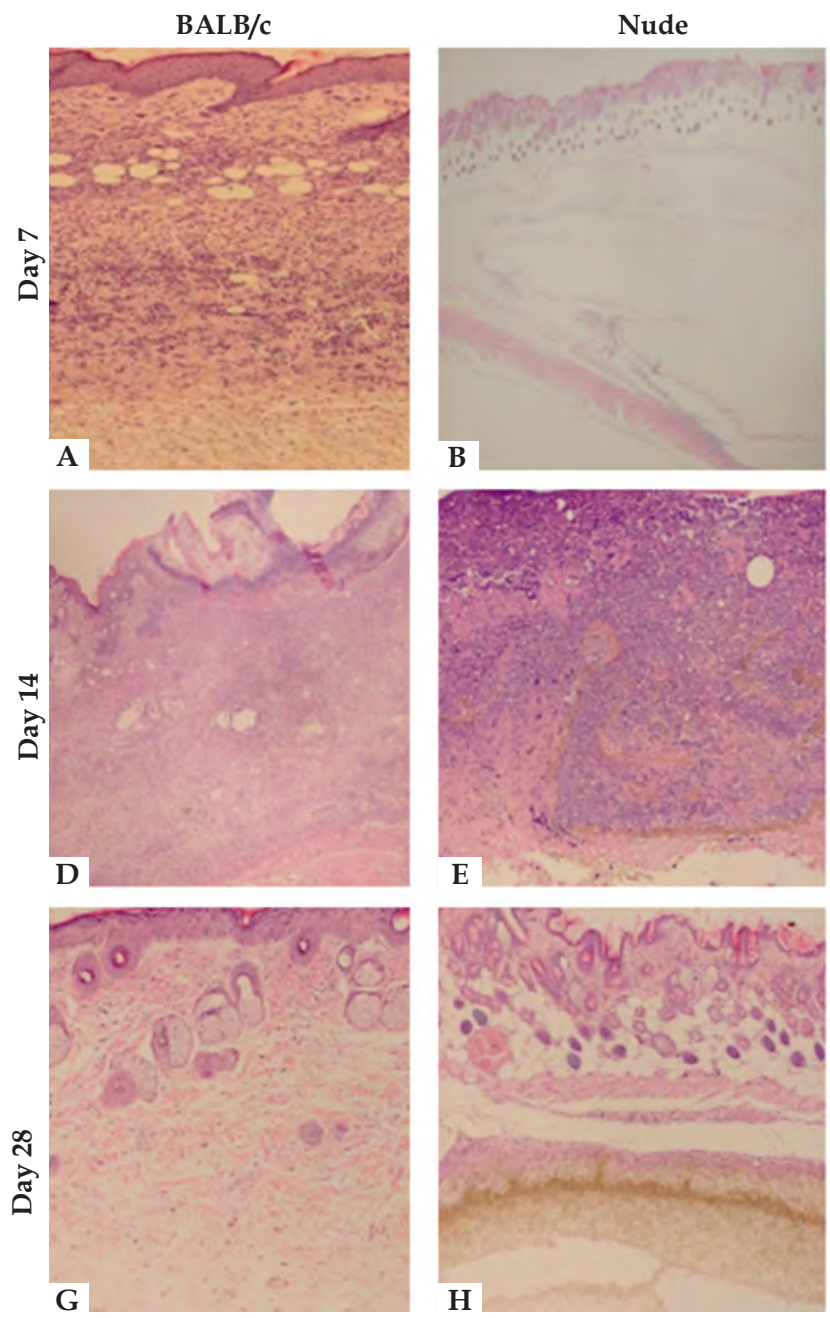
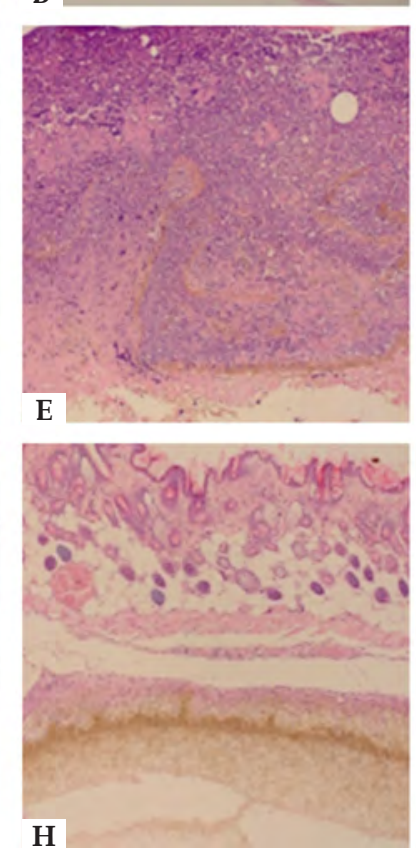

SCID
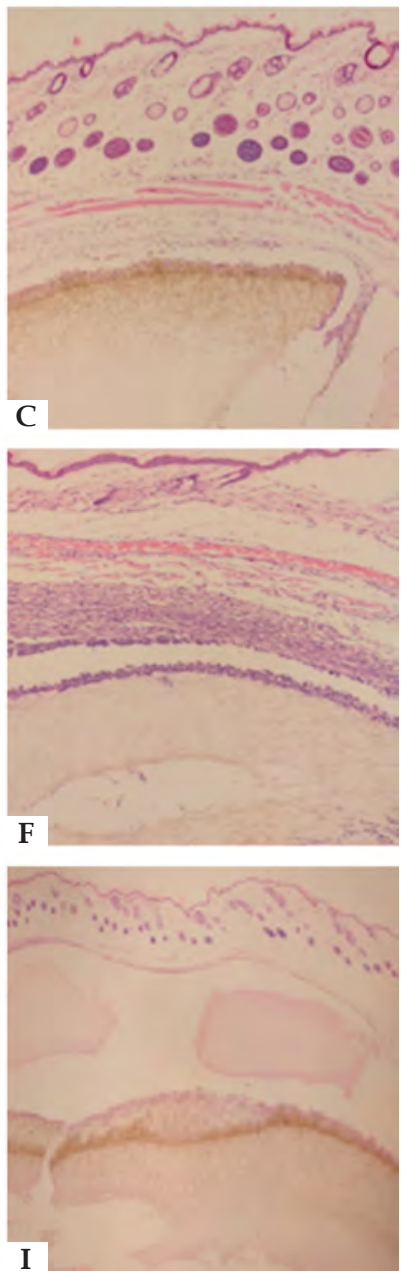

Figure 2: The inflammatory process induced after fungal implantation in the site of fungal implantation. On day 7: (A) BALB/c showed neutrophilic infiltration compared to (B) Nude and (C) SCID. On day 14: A granulomatous infiltration was observed in (D) BALB/c and (E) Nude, but not in (F) SCID. On day 28: The inflammatory process was eliminated in (G) BALB/c, and the neutrophilic infiltration persisted in $(\mathbf{H})$ Nude and (I) SCID (Hematoxylin \& eosin, $x 40$ ) 
nocompromised mice infected with F. pedrosoi. In fact, F. pedrosoi is the most frequent etiologic agent for chromoblastomycosis and it was also described as an agent for phaeohyphomycosis, particularly in immunocompromised patients. ${ }^{5}$ These fungi are found in nature, especially in the soil, and are characterized by melanin in the cell, which gives the dark color and increased fungal resistance. There are many factors that affect the immunity response against a fungal infection including route of infection, the size of the inoculum and the fungal life cycle forms (hyphae, conidia, conidiogenous cells and yeasts). Therefore, there are distinct resistance patterns against the infection and immune response of the host.

As a consequence of the increased number of immunocompromised patients due to cancer, diabetes, AIDS and organ transplant, opportunistic fungal infections have been reported more frequently. It is known that defects in innate immunity that lead to neutropenia or reduction of phagocyte activity predispose patients to disseminated infections caused by Candida e Aspergillus, while T-cell dysfunction predisposes to cryptococcosis. ${ }^{12}$ In comparison to these infectious fungal diseases, immunology related to F. pedrosoi infection is still little know.

Previous studies supported the hypothesis of a failure in the innate immunity as the main cause for chromoblastomycosis, demonstrated by the ability of $F$. pedrosoi to survive and proliferate in macrophages, with the activated macrophages being fungistatic instead of fungicidal for these pathogens. ${ }^{6,13}$ A recent study showed that the chronic nature of the infection by F. pedrosoi is due to an innate failure in murine models. ${ }^{14}$ Neutrophils have an important role in fungal infection and in this study, we observed an important
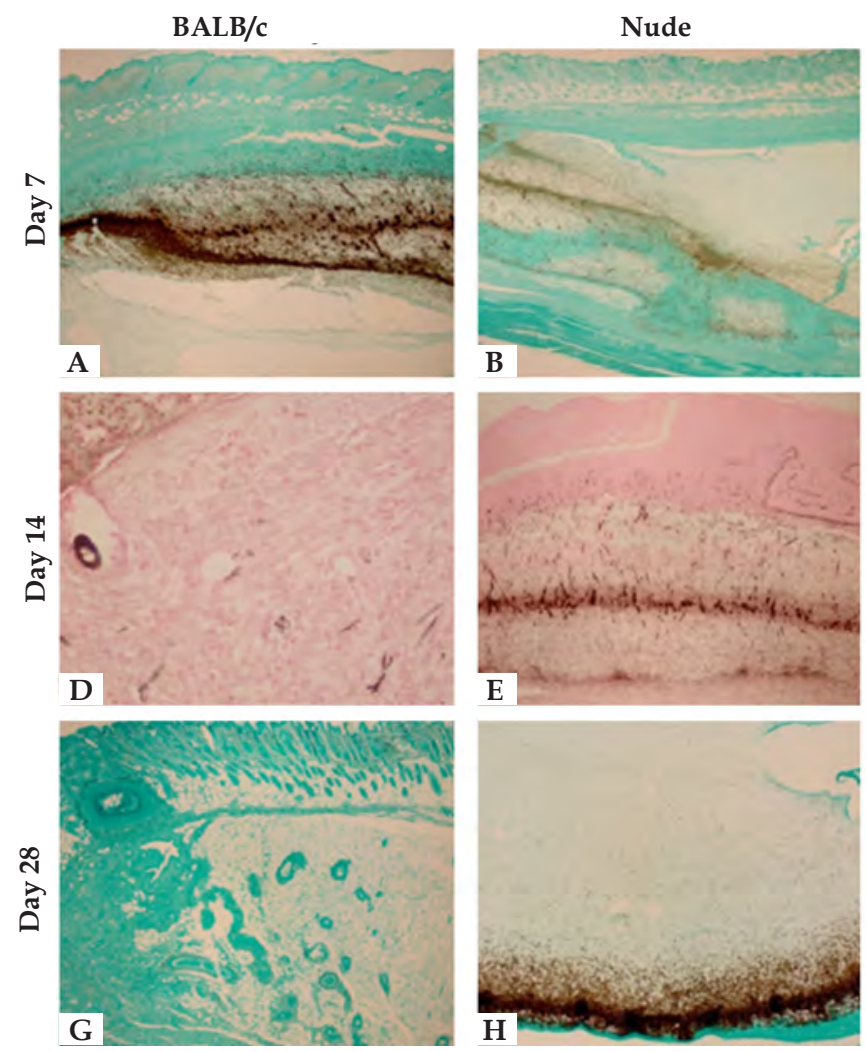

acute inflammatory response made by neutrophils in the early stages of infection (day 7). The amount of neutrophils varied according to the mice strain. In Nude and SCID mice, two strains that do not have mature $\mathrm{T}$ lymphocytes and B and T lymphocytes, respectively, the neutrophilic infiltration was smaller than that observed in other mice strains. This is partially explained due to the influence of lymphocytes in the recruitment of neutrophils, particularly Th17, in order to control the initial infectious process. ${ }^{15}$ We also observed that neutrophils tend to control the infection, since it was clear that the agar gel with fungi was totally surrounded by neutrophils to avoid

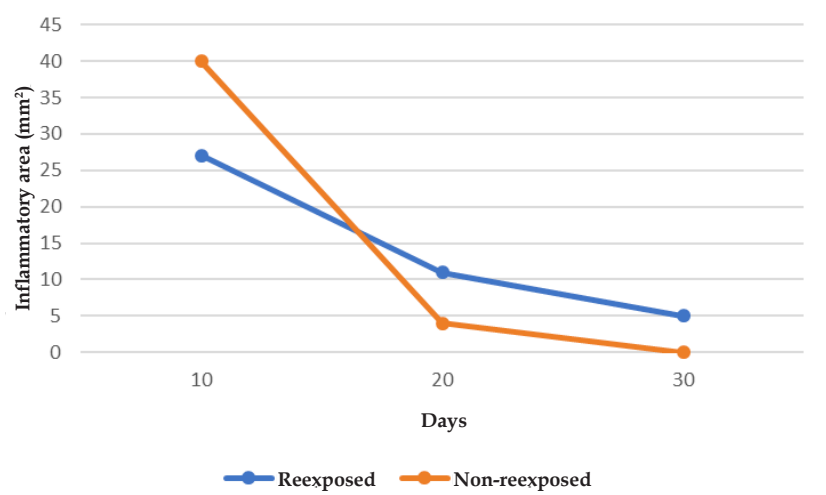

Graph 1: Mean inflammatory areas $\left(\mathrm{mm}^{2}\right)$ of mice reexposed to $F$. pedrosoi (blue line) and non-reexposed (orange line), on days 10, 20 and 30 ( $n=6$ animals for each group of mice). On day 10, non-reexposed mice showed a significant increase in the inflammatory area in comparison to reexposed mice $(p=0.015)$. On days 20 and 30 there was no significant differences between both groups
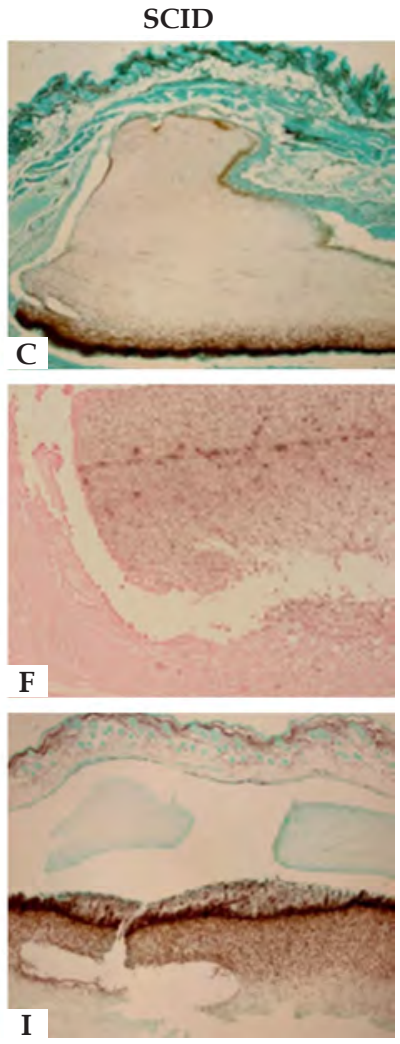

Figure 3: Histologic analysis of fungal mass. On day 7 , the fungal mass is organized as a line in A BALB/c different than B - Nude and C - SCID, where fungi tend to penetrate muscle tissue (Grocott stain, x40). On day 14, fungi were moving towards the surface in $\mathbf{D}$ $\mathrm{BALB} / \mathrm{c}$ and $\mathbf{E}$ - Nude but not in $\mathbf{F}$ - SCID (Fontana-Masson, x40). On day 28, the fungal mass was eliminated in G - BALB/c but remained intact in $\mathbf{H}$ - Nude and I - SCID (Grocott, x40) 

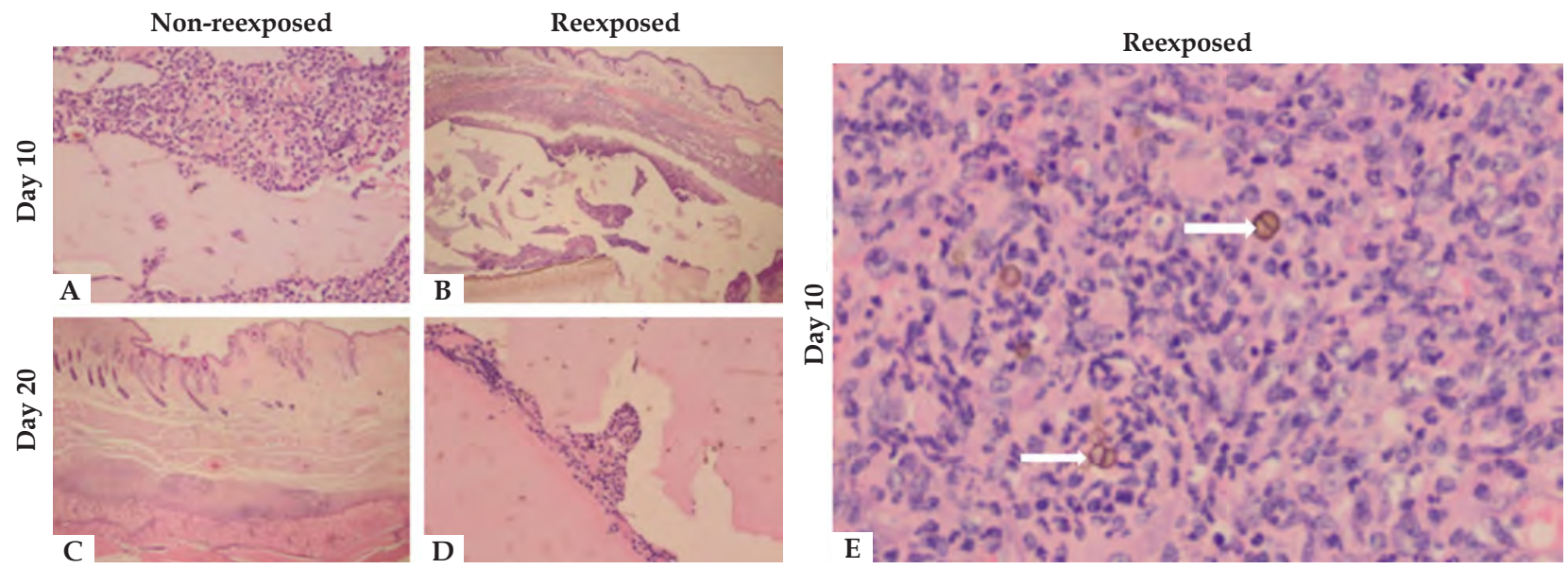

Figure 4: Histologic analysis comparing the group of mice not reexposed to F. pedrosoi to the group reexposed on day 10 and 20 after fungal implantation (Hematoxylin \& eosin, x40). On day 10, A - in the non-reexposed group, neutrophilic infiltration was more intense than in the reexposed group $\mathbf{B}$ - and, in this group, there was also granulomatous infiltration. On day 20, fungi were absent in group C - non-reexposed and present in group D - reexposed. On day 10, the presence of muriform cells (arrows) was observed in E - reexposed mice. Hematoxylin \& eosin, $x 100$

fungal spread even among immunodeficient mice. This can be explained by the ability of neutrophils in forming extracellular traps of neutrophils (NET). ${ }^{16}$ On day 7 , fungi remained as a line in BALB/c and Nude-r mice. In SCID and Nude mice, fungi penetrated muscle tissue but did not spread. Clinically, this acute neutrophil inflammatory process was represented as a nodular lesion in all mice strains.

In addition to this acute inflammatory response, BALB/C and Nude-r showed early on a repair tissue composed of pseudocapsule, fibrosis and vascular neoformation, demonstrating an early resolution of the infectious process. It is interesting to point out the presence of vacuolated macrophages in SCID and Nude mice, since these cells are present in resistant forms of pathogens, such as diffuse cutaneous leishmaniasis and lepromatous leprosy. These two observations could add significant information to the clinical scenarios.

The experimental infection in mice also showed the importance of the cellular immunity in the infection by F. pedrosoi. Nude mice developed a more chronic disease when compared to normal BALB/c mice. ${ }^{17}$ CD4 -/- mice showed a worse progression when inoculated with $F$. pedrosoi. ${ }^{10}$ Our study reinforced the importance of T-cells in the elimination of fungi by mice. Immunocompromised Nude and SCID mice were not able to overcome the infection. Consequently, on day 28 , the fungal inoculum was still present. However, when Nude mice were reconstituted with T-cells, they were able to eliminate the fungi in the same period of time as normal $\mathrm{BALB} / \mathrm{c}$ mice. In this experiment, we observed the granulomatous inflammatory process between day 7 and 14 after fungal inoculation, except in SCID mice, that did not demonstrate this inflammatory process but only a small neutrophilic infiltrate surrounding the gel with fungi. BALB/c and Nude-r mice showed a compact granuloma rich in neutrophilic infiltrate. Nude mice also presented a granulomatous inflammatory infiltrate, but the distribution was diffuse, different than detected in mice. Clinically, on day 14, we observed a black material being expelled through the nodules in all mice, except SCID mice. The spontaneous process of fungal elimination from the dermis to the epidermis and restoration of the epidermis after fungal elimination is known as transepithelial elimination, which occurred in all mice strains, except for SCID mice. ${ }^{18}$ According to our results, this phenomenon could be associated to the granulomatous inflammatory process.

It is interesting to observe the nodular lesion that persisted in Nude and SCID mice on day 28, clinically similar to subcutaneous phaeohyphomycosis seen mainly in immunocompromised patients. In our previous study, we followed 17 renal transplant recipients who were diagnosed with phaeohyphomycosis: 15 of them had a cystic lesion similar to those found in immunodeficient mice. ${ }^{5}$ To avoid rejection of the transplanted organ. Those patients used immunosuppressant medications that inhibited the activation and proliferation of T- and B-cells. ${ }^{19}$ This observation corroborates the hypothesis that the clinical spectrum of diseases caused by melanized fungi depends on the dynamic interactions between the etiological agent and the immune status of the host. In fact, phaeohyphomycosis is more frequently reported in immunocompromised individuals. ${ }^{20}$

This study emphasized the role of the two arms of the immune system: the innate immunity, with the active participation of neutrophils, and the adaptive immunity, with $\mathrm{T}$ lymphocytes as the essential elements to eliminate F. pedrosoi infection in mice. The ability of immunocompetent mice to eliminate the infection caused by F. pedrosoi is known and was also demonstrated in this study. ${ }^{17}$ The induction of the chronicity of this fungal infection in mice to transform hyphae in muriform cells in the tissue has been a challenge. These muriform cells are a resistant state of these fungi found in chromoblastomycosis.

Chromoblastomycosis is common among rural workers who many times are injured, facilitating the penetration of fungi in the skin. In an attempt to simulate the natural implantation of fungi in the skin, we performed two inoculations in the subcutaneous tissue of C57BL/ 6 mice in different timeframes. We observed that the reexposure to the fungi induced a lower degree of acute neutrophilic inflammatory process in comparison to mice that were 
not reexposed, and a delayed resolution of the infectious process. In contrast, mice exposed to fungi in one site developed an intense inflammatory process made mainly by neutrophils, that was subsequently followed by a compact granulomatous process and fungal elimination. Fungal elimination occurred on day 20 in the non-reexposed group and on day 30 in the reexposed group. However, both groups were able to clear the infectious process.

We demonstrated that the repeat implantation of fungi is associated to chronicity of the infectious process, which is also observed in patients with verrucous lesions with a compact tuberculoid granulomatous process. Reexposure to F. pedrosoi can induce a tolerance mechanism in the host, limiting the elimination of patho- gens and their persistence in the tissue. ${ }^{21}$ We also observed the appearance of muriform cells in the second site of inoculation, which could confirm the hypothesis of chronicity of infections. ${ }^{22}$

\section{CONCLUSION}

This study showed histologically the role of the neutrophilic infiltration in halting the infection and in the prevention of fungal spread in immunodeficient mice. But the fungal elimination depended on T lymphocytes. Reexposure of C57BL/ 6 mice to F. pedrosoi caused a delayed resolution of the infection. The appearance of muriform cells could indicate that the reexposure to the fungus can lead to chronicity of the infection.

\section{REFERENCES}

1. Revankar SG, Sutton DA. Melanized fungi in human disease. Clin Microbiol Rev. 2010;23:884-928.

2. Hoffmann Cde C, Danucalov IP, Purim KS, Queiroz-Telles F. Infections caused by dematiaceous fungi and their clinical correlations. An Bras Dermatol. 2011;86:138-41.

3. García-Martos P, Márquez A, Gené J. Human infections by black yeast of genus Exophiala. Rev Iberoam Micol. 2002;19:72-9.

4. Saha R, Rudra S. Phaeomycotic cyst - a case report. J Indian Med Assoc. 2005;103:555-6.

5. Ogawa MM, Galante NZ, Godoy P, Fischman-Gompertz 0, Martelli F, Colombo AL, et al. Treatment of subcutaneous phaeohyphomycosis and prospective follow-up of 17 kidney transplant recipients. J Am Acad Dermatol. 2009;61:977-85.

6. Rozental S, Alviano CS, de Souza W. The in vitro susceptibility of Fonsecaea pedrosoi to activated macrophages. Mycopathologia. 1994;126:85-91.

7. Schnitzler N, Peltroche-Llacsahuanga H, Bestier N, Zündorf J, Lütticken R, Haase G. Effect of melanin and carotenoids of Exophiala (Wangiella) dermatidis on phagocytosis, oxidative burst, and killing by human neutrophils. Infect Immun. 1999;67:94-101.

8. d'Avila SC, Pagliari C, Duarte MI. The cell-mediated immune reaction in the cutaneous lesion of chromoblastomycosis and their correlation with different clinical forms. Mycopathologia. 2003;156:51-60.

9. Gimenes VMF, de Souza MG, Ferreira KS, Marques SG, Gonçalves AG, Santos DVGL. Cytokines and lymphocyte proliferation in patients with different clinical forms of chromoblastomycosis. Microbes Infect. 2005;7:708-13.

10. Teixeira de Sousa Mda G, Ghosn EE, Almeida SR. Absence of CD4+T cells impairs host defense of mice infected with Fonsecaea pedrosoi. Scand J Immunol. 2006;64:595-600.
11. Miyaji M, Nishimura K. Invetigation on dimorphism of Blastomyces dermatitidis by agar-implantation method. Mycopathologia. 1977;60:73-8.

12. Mansour MK, Levitz SM. Interactions of fungi with phagocytes. Curr Opin Microbiol. 2002;5:359-65.

13. Farbiarz SR, De Carvalho TU, Alviano C, De Souza W. Fine structure and cytochemistry of the interaction between Fonseacea pedrosoi and mouse resident macrophage. J Med Vet Mycol. 1990;28:373-83.

14. Sousa Mda G, Reid DM, Schweighoffer E, Tybulewicz V, Ruland J, Langhorne $\mathrm{J}$, et al. Restoration of pattern recognition receptor costimulation to treat chromoblastomycosis, a chronic fungal infection of the skin. Cell Host Microbe. 2011;9:436-43.

15. Romani L. Cell mediated immunity to fungi: reassessment. Med Mycol. 2008;46:515-29.

16. Brinkmann V, Reichard U, Goosmann C, Fauler B, Uhlemann Y, Weiss DS, et al. A neutrophil extracellular traps kill bacteria. Science. 2004;303:1532-5.

17. Ahrens J, Graybill JR, Abishawl A, Tio FO, Rinaldi MG. Experimental murine chromomycosis mimicking chronic progressive human disease. Am J Trop Med Hyg. 1989;40:651-8.

18. Mehregan AH. Transepithelial elimination. Curr Probl Dermatol. 1970;3:124-47.

19. Fries D, Kechrid C, Charpentier B, Hammouche M, Moulin B. A prospective study of a triple association cyclosporine, corticosteroids and azathioprine in immunological high-risk renal transplantation. Transpl Proc. 1985;17:1231-4.

20. Silveira F, Nucci M. Emergence of black moulds in fungal disease: epidemiology and therapy. Curr Opin Infect Dis. 2001;14:679-84.

21. Machado AP, Silva MR, Fischman 0. Prolonged infection by Fonsecaea pedrosoi after co-stimulation at different sites in experimental murine chromoblasotmycosis. Virulence. 2010;1:29-36.

22. Rosen T, Overholt M. Persistent viability of Medlar body. Int J Dermatol. 1996;35:96-8. 


\section{AUTHORS'CONTRIBUTIONS}

Marilia Marufuji Ogawa

(iD) ORCID

0000-0002-8073-923X

Conception and planning of the study; Elaboration and writing of the manuscript; Obtaining, analyzing and interpreting the data
Jane Tomimori
(iD) ORCID
0000-0002-2407-6646

Conception and planning of the study; Effective participation in research orientation

Mario Mariano

(iD) ORCID 0000-0003-4664-172X

Conception and planning of the study; Effective participation in research orientation

Nilceo Schwery Michalany

(iD) ORCID 0000-0002-9300-163X

Obtaining, analyzing and interpreting the data

Maria Regina Regis Silva

(iD) ORCID 0000-0001-8443-8154

Obtaining, analyzing and interpreting the data

Milvia Maria Simões e Silva Enokihara
Obtaining, analyzing and interpreting the data

Angela Satie Nishikaku

(D) ORCID 0000-0002-3340-4074

Elaboration and writing of the manuscript; Critical review of the manuscript
Agenor Messias Silvestre Junior
(iD) ORCID
0000-0001-5104-9363

Obtaining, analyzing and interpreting the data

How to cite this article: Ogawa MM, Mariano M, Silva MRR, Enokihara MMSS, Michalany NS, Nishikaku AS, Silvestre AM, Tomimori J. Study of tissue inflammatory response in different mouse strains infected by dematiaceous fungi Fonsecaea pedrosoi. An Bras Dermatol. 2019;94(1):29-36. 